\title{
Evaluación del funcionamiento de un prototipo de electrofloculación para el tratamiento de agua residual proveniente de procesos de biodigestión y biocompostaje
}

\section{Evaluation of the operation of an electroflocculation prototype for the treatment of residual water from biodigestion and biocomposting processes}

\author{
ALFONSO-ALVAREZ, Juan Antonio †*, MONTAÑO-SOTO, Myriam Tatiana, EATON-GONZÁLEZ, \\ Bernardino Ricardo y VÉLIZ-ZAMORANO, Ana Karina
}

Universidad Tecnológica de Tijuana

ID $1^{\mathrm{er}}$ Autor: Juan Antonio, Alfonso-Alvarez / ORC ID: 0000-0002-3925-1662, Researcher ID Thomson: H-8445-2018, CVU CONACYT ID: 412788

ID $1^{\mathrm{er}}$ Coautor: Myriam Tatiana, Montaño-Soto / ORC ID: 0000-0003-0741-9173, CVU CONACYT ID: 324049

ID $2^{\text {do }}$ Coautor: Bernardino Ricardo, Eaton-González / ORC ID: 0000-0003-4528-4740, Researcher ID Thomson: F-79062012, CVU CONACYT ID: 94473

ID $3^{\text {er }}$ Coautor: Ana Karina, Véliz-Zamorano / ORC ID: 0000-0002-8894-4430, CVU CONACYT ID: 527944

DOI: $10.35429 /$ JOES.2019.20.6.8.15

Recibido: 11 de Junio, 2019; Aceptado 30 de Septiembre, 2019

\begin{abstract}
Resumen
Introducción. En los últimos años el Gobierno de Baja California ha promovido no descargar agua residual con alto contenido de grasas y aceites. Una empresa de la región dedicada a la recolección de lodos, decidió instalar un sistema de centrifugado horizontal para la extracción de aceite, generando un lodo con 5\% de grasa y aceite, el cual se envía a un proceso de biodigestión y lombricomposta para la generación de humus sólido y líquido, generando aguas residuales con alta carga orgánica que requieren de un tratamiento antes de su disposición. Objetivo: Elaborar un prototipo experimental de electrofloculación para el tratamiento de agua residual (TAR) con alto contenido de materia orgánica. La Metodología se dividió en 4 etapas: 1) Caracterización de parámetros fisicoquímicos y biológicos del agua residual; 2) Montaje del prototipo; 3) Experimentación; 4) Verificación del Sistema. Contribución. Mediante la elaboración del prototipo se confirmó de la efectividad del proceso de electrofloculación para el TAR con un alto contenido de materia orgánica y bacterias patógenas, ya que se logró una disminución mayor al 50\% en la presencia de DBO5 (demanda bioquímica de oxígeno), DQO (demanda química de oxígeno), coliformes fecales y Salmonella.
\end{abstract}

Electrofloculación, Caracterización, Prototipo

\begin{abstract}
Introduction. In recent years, the Government of Baja California has promoted not to discharge wastewater with high content of fats and oils. A company in the region dedicated to the collection of sludge, installed a horizontal centrifugation system for the extraction of oil, generating a sludge with 5\% fat and oil. The result of this process is sent to a process of biodigestion and vermicompost for the generation of solid and liquid humus, which generates wastewater with high organic load that require a treatment before disposal. Objective. Develop an experimental prototype of electroflocculation to wastewater treatment with a high content of organic matter. Methodology was divided into 4 stages: 1) Physicochemical and biological characterization of the wastewater; 2) Assembly of the electroflocculation prototype; 3) Experimental assessment 4) Verification of system operation. Contribution. Through the elaboration of the prototype, the effectiveness of the electroflocculation process was confirmed for the wastewater treatment (WT) with a high content of organic matter (OM) and pathogenic bacteria, since a greater than $50 \%$ decrease of the biochemical oxygen demand (BOD5), chemical demand of oxygen (COD), fecal coliforms and Salmonella.
\end{abstract}

Electroflocculation, Characterization, Prototype

Citación: ALFONSO-ALVAREZ, Juan Antonio, MONTAÑO-SOTO, Myriam Tatiana, EATON-GONZÁLEZ, Bernardino Ricardo y VÉLIZ-ZAMORANO, Ana Karina. Evaluación del funcionamiento de un prototipo de electrofloculación para el tratamiento de agua residual proveniente de procesos de biodigestión y biocompostaje. Revista de Sistemas Experimentales. 2019. 6-20: 8-15

\footnotetext{
* Correspondencia del Autor (juan.alfonso@uttijuana.edu.mx)

$\dagger$ Investigador contribuyendo como primer autor.
} 


\section{Introducción}

En los últimos años el Gobierno del Estado de Baja California ha promovido la recolección de grasas y aceites residuales provenientes de la industria restaurantera, para evitar el problema ocasionado por descargas no controladas de agua con un alto contenido de grasas y aceites, que trae como consecuencia el taponamiento del sistema de drenaje y una baja eficiencia en el sistema de tratamiento de agua residuales de la ciudad de Tijuana, Baja California, en donde se cuenta con infraestructura para tratar el $100 \%$ del agua residual.

Derivado de dichas medidas los restaurantes y negocios dedicados a la producción de alimentos deben contar con trampas de grasas y aceites, con la finalidad de recolectar la mayor cantidad posible de este residuo. Las trampas de grasas se deben limpiar periódicamente para garantizar su buen funcionamiento, lo que genera residuos con alto contenido de grasas y aceites (lodos con hasta un $50 \%$ de grasas y aceites), que deben disponerse de forma adecuada mediante el pago de servicios de recolección.

\section{Problemática}

Uno de los principales problemas de la recolección de residuos provenientes de trampas de grasas y aceites es que debido a su naturaleza química, el residuo se considera peligroso y no puede ser dispuesto directamente en el suelo. Es necesario enviarlo a un sistema de confinamiento, generando altos costos a las empresas dedicadas a su recolección.

Lo anterior motivó a una empresa ubicada en la región, dedicada a la recolección de lodos, a instalar un sistema de centrifugado horizontal para la extracción de aceite, generando un lodo con $5 \%$ de grasa y aceite, el cual posteriormente se envía a un proceso de biodigestión y lombricompostaje para la obtención de humus sólido y líquido, este sistema genera aguas residuales con alta carga orgánica que requieren de un tratamiento antes de su descarga a la red municipal de alcantarillado de la Ciudad.

\section{Justificación}

Debido a los procesos biológicos utilizados en la degradación de los lodos provenientes de trampas de grasas y aceites, se generan aguas residuales con un alto contenido de materia orgánica y coliformes fecales.

Las aguas residuales generadas requieren de un tratamiento que permita su disposición o reúso. La implementación de un sistema de tratamiento de electrofloculación, que consiste en la remoción de contaminantes que se encuentran en suspensión o disueltos, mediante la inducción de corriente eléctrica en la fase acuosa, a través de electrodos metálicos como aluminio, dispuestos en paralelo permitirá el cumplimiento de la NOM-002-SEMARNAT1996, que establece los límites máximos permisibles de contaminantes en las descargas de aguas residuales a los sistemas de alcantarillado urbano o municipal (Prieto García, Callejas Hernández, Reyes Cruz, \& Marmolejo Santillán, 2012). Debido a lo anterior se propuso como objetivo de esta investigación: Elaborar un prototipo experimental de electrofloculación para verificar su efectividad en el tratamiento de agua residual (TAR) con alto contenido de materia orgánica (MO) y bacterias patógenas.

\section{Metodología}

El funcionamiento del prototipo se basó en aplicar al agua residual una corriente eléctrica mediante la incorporación de dos electrodos de aluminio, logrando que se desestabilicen los contaminantes suspendidos o disueltos en el agua, mediante la producción burbujas de oxígeno en el ánodo y de hidrógeno en el cátodo permitiendo la formación flóculos de contaminante en la superficie del reactor lo que permite una fácil separación (Aldeguer, Prats , \& Seller, 2019). El desarrollo del prototipo de electrofloculación se dividió en 4 etapas: 1) Caracterización de parámetros fisicoquímicos y biológicos del agua residual; 2) Diseño y montaje del prototipo; 3) Experimentación; 4) Verificación del sistema

\section{Caracterización de parámetros fisicoquímicos y biológicos del agua residual.}

Con la finalidad de conocer las características del agua residual se realizaron los análisis físicos, químicos y biológicos que se muestra la tabla1. 
Para la medición pH se utilizó un medidor de $\mathrm{pH}$ de la marca Thermoscientific, modelo Orion Start A111 con compensador de temperatura. Para la conductividad eléctrica se utilizó un conductímetro HANNA Waterproof con compensador de temperatura con una resolución de $1 \mu \mathrm{S} / \mathrm{cm}$.

\begin{tabular}{|c|c|c|}
\hline Parámetro & Método & $\begin{array}{l}\text { Norma de } \\
\text { referencia }\end{array}$ \\
\hline $\mathrm{pH}$ & Potenciometría & $\begin{array}{l}\text { NMX-AA- } \\
008-S C F I- \\
2016\end{array}$ \\
\hline $\begin{array}{l}\text { Conductividad } \\
\text { Eléctrica }\end{array}$ & Potenciometría & $\begin{array}{l}\text { NMX-AA- } \\
\text { 093-SCFI- } \\
2018\end{array}$ \\
\hline Grasas y Aceites & Extracción Soxhlet & $\begin{array}{l}\text { NMX-AA- } \\
005-S C F I- \\
2013\end{array}$ \\
\hline $\begin{array}{l}\text { Sólidos } \\
\text { Sedimentables }\end{array}$ & Cono Imhoff & $\begin{array}{l}\text { NMX-AA- } \\
004-S C F I- \\
2013\end{array}$ \\
\hline Nitrógeno Total & Kjeldahl & $\begin{array}{l}\text { NMX-AA- } \\
026-S C F I- \\
2010\end{array}$ \\
\hline Escherichia coli & $\begin{array}{l}\text { Número Más } \\
\text { Probable (NMP) }\end{array}$ & $\begin{array}{l}\text { NMX-AA- } \\
042-S C F I- \\
2015\end{array}$ \\
\hline $\begin{array}{l}\text { Demanda } \\
\text { bioquímica de } \\
\text { oxígeno (DBO5) }\end{array}$ & Electrométrico & $\begin{array}{l}\text { NMX-AA- } \\
028-S C F I- \\
2001\end{array}$ \\
\hline $\begin{array}{l}\text { Demanda Química } \\
\text { de oxígeno (DQO) }\end{array}$ & Volumétrico & $\begin{array}{l}\text { NMX-AA- } \\
030 / 1-S C F I- \\
2012\end{array}$ \\
\hline Salmonella sp. & Preenriquecimiento & $\begin{array}{l}\text { NOM-114 } \\
\text { SSA1-1994 }\end{array}$ \\
\hline
\end{tabular}

Tabla 1 Parámetros analizados al agua residual Fuente: Elaboración Propia

La determinación de grasas y aceites se realizó mediante el método de extracción Soxhlet, que consiste en la extracción de grasa y aceite utilizando hexano como solvente de extracción, en ciclos de aproximadamente 3 minutos para un total de 20 ciclos por hora. Los sólidos sedimentables se midieron como la cantidad de sólidos depositados en el fondo de un cono Imhoff en un periodo de $60 \mathrm{~min}$, de conformidad con la NMX-AA-004-SCFI-2013.

La determinación de nitrógeno total se realizó mediante el método Kjeldahl, se utilizó sistema de digestión combinado de la marca CRAFT modelo KC-1600V. El método consistió en digerir la muestra mediante el empleo de una solución acida, para posteriormente realizar la destilación, y la solución recolectada se tituló con una solución de ácido sulfúrico 0.006 M.La determinación de $\mathrm{DBO}_{5}$ se realizó mediante el método electrométrico, para la medición de oxígeno disuelto (OD) que se realizó antes y después de los 5 días incubación se utilizó un medidor Milwaukee modelo MW 600.
La DQO se realizó mediante una oxidación con Dicromato de Potasio, el exceso de Dicromato se valoró con una solución de Tiosulfato de Sodio.

Los parámetros biológicos de Escherichia Coli y Salmonella se realizaron mediante la técnica del número más probable (NMP). Para la determinación de E. Coli se realizó inicialmente una prueba presuntiva con medio de cultivo caldo Lauril Sulfato, la prueba confirmativa se realizó a los tubos positivos mediante su inoculación en caldo Billis Verde Brillante a $45^{\circ} \mathrm{C}$. Finalmente la presencia de $E$. Coli se confirmó mediante la inoculación de los tubos positivos en Caldo E.C.

Para la determinación de Salmonella el método se dividió en 4 etapas: 1) Preenriquecimiento; 2) Enriquecimiento selectivo; 3) Sembrado en placa con agar XLD (Xilosa Lisina Desoxicolato) y Agar VB (Billis Verde brillante); 4) identificación bioquímica mediante medio TSI (Hierro-Triple Azúcar)

\section{Montaje del prototipo de electrofloculación}

Para definir el sistema de electrofloculación a escala laboratorio, primero se procedió a identificar la capacidad de volumen del reactor, los materiales y equipos para su elaboración. Se decidió un volumen $1000 \mathrm{~mL}$, electrodos de aluminio (Vasudevan, 2012) tanto ánodo como cátodo de aproximadamente $40 \mathrm{~cm}^{3}$ cada uno, en forma de placa (Chen, 2004), con finalidad que en condiciones ácidas genere hidrógeno para que arrastre los flóculos generados hacia la parte superior. Con una distancia entre electrodos de 4 cm. (Ozyonar \& Karagozoglu, 2011).

También se integró al sistema una fuente de poder de la marca B\&K PRECISION modelo 1672 , con un rango de voltaje de 0 a 99V y rango de amperaje de 0 a 9.99 Ampere, para controlar la intensidad de corriente a la celda (Mendoza Burgos \& Sánchez Guzmán, 2019). Elegidos los componentes se decidió que el prototipo debería estar integrado por una fuente de poder, un sistema de reacción con un ánodo y un cátodo de aluminio, y un sistema de agitación. 


\section{Experimentación}

Definido el prototipo se procedió a determinar los parámetros de trabajo. Considerando el volumen del agua, $\mathrm{pH}$ de trabajo, diferencia de potencial e intensidad de corriente, factores de suma importancia, ya que se ha demostrado que se obtienen altos porcentajes en la disminución de la DQO cuando se disminuye el pH (Arango Ruiz \& Garcés Giraldo, 2007). También se consideró el tiempo de reacción y se realizaron por lo menos 20 corridas experimentales.

La experimentación consistió en ajustar el pH del agua a 4 con una solución ácido clorhídrico $1 \mathrm{M}$, para posteriormente aplicar una intensidad de corriente de 8 Amperes y un voltaje de $34 \mathrm{~V}$ durante 5 minutos. Finalmente el agua obtenida en el proceso de electrofloculación se pasó por un tratamiento físico, que consistió en la filtración con carbón activado para la eliminación de color y malos olores.

\section{Verificación del sistema}

Para verificar la efectividad del sistema de tratamiento, se procedió a determinar las características físicas, químicas y biológicas del agua tratada mediante el sistema de electrofloculación. Los parámetros considerados fueron los mismos que para el agua residual además se incluyeron la determinación de dureza, sólidos disueltos totales y sulfatos, las técnicas utilizadas fueron las mismas técnicas descritas en el apartado 4.1.

Para la determinación de dureza total se hizo referencia al método descrito en la Norma Mexicana (Norma Mexicana NMX-AA-072SCFI-2001, 2001), que consiste en una valoración con disolución de EDTA $0.01 \mathrm{M}$, empleando un indicador negro de Eriocromo T, para la cuantificación de $\mathrm{CaCO}_{3}$, y la determinación de sulfatos mediante el método turbidimétrico (Norma Mexicana NMX-AA074-SCFI-2014, 2015) para el que se utilizó un espectrofotómetro UV-VIS Agilent Technologies modelo Cary 60.

\section{Resultados}

Los resultados para cada una de las etapas llevadas a cabo para la evaluación del funcionamiento del prototipo de electrofloculación para el tratamiento de agua residual proveniente de procesos de biodigestión y biocompostaje se muestran a continuación:

\section{Etapa 1. Caracterización de parámetros fisicoquímicos y biológicos del agua residual}

En la tabla 2, se presentan los resultados de la determinación de los parámetros físicos, químicos y biológicos del agua residual antes del proceso de electrofloculación.

\begin{tabular}{|l|l|l|}
\hline \multicolumn{2}{|l|}{$\begin{array}{l}\text { Parámetro } \\
\text { promedio }\end{array}$} & $\begin{array}{l}\text { Límite } \\
\text { permisible } \begin{array}{r}\text { máximo } \\
\text { NOM-SEMARNAT- } \\
1996\end{array}\end{array}$ \\
\hline $\mathrm{pH}$ & 7.3 & $5.5-10$ \\
\hline $\begin{array}{l}\text { Conductividad } \\
\text { Eléctrica (mS/m) }\end{array}$ & 10.3 & Sin Especificación \\
\hline $\begin{array}{l}\text { Grasas y Aceites } \\
\text { (mg/L) }\end{array}$ & 13 & 25 \\
\hline $\begin{array}{l}\text { Sólidos } \\
\text { Sedimentables } \\
\text { (mL/L) }\end{array}$ & 0.6 & 5 \\
\hline $\begin{array}{l}\text { Nitrógeno Total } \\
\text { (mg/L) }\end{array}$ & 4.92 & 40 \\
\hline $\begin{array}{l}\text { Escherichia Coli } \\
\text { por cada 100 mL, } \\
\text { NMP }\end{array}$ & 210 & Sin Especificación \\
\hline DBO5 (mg/L) & 500 & 150 \\
\hline DQO (mg/L) & 883.2 & Sin especificación \\
\hline Salmonella/100 mL & Presencia & Sin Especificación \\
\hline
\end{tabular}

Tabla 2. Resultados de caracterización del agua residual Fuente: NOM-002-SEMARNAT

Como se puede observar la mayoría de los parámetros se encuentran dentro de la especificaciones de la NOM-002-SEMARNAT1996, sin embargo los parámetros de $\mathrm{DBO}_{5} \mathrm{y}$ DQO se encuentra por encima del doble de lo especificado por la norma, debido a la naturaleza del agua residual proveniente de un proceso de digestión, y por ende un alto contenido de E.coli y presencia de Salmonella sp.

\section{Etapa 2. Montaje del prototipo de electrofloculación}

Identificado el material se procedió a la construcción del prototipo, que consistió en una fuente de poder, un sistema de reacción que contiene un ánodo y un cátodo de aluminio situados de forma monopolar, y un sistema de agitación (Mollah, y otros, 2004), como se muestra en la figura 1. 


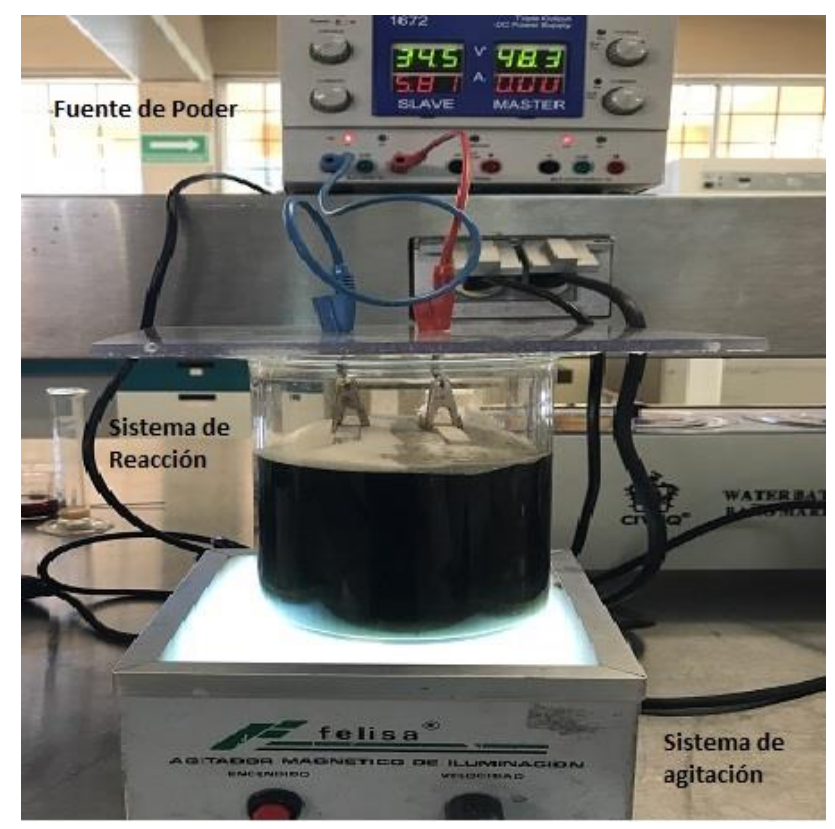

Figura 1 Componentes del sistema de electrofloculación Fuente: Elaboración Propia

\section{Etapa 3. Experimentación.}

Construido el sistema de electrofloculación el pH se ajustó a 4 , ya que debido a los resultados de las pruebas experimentales prospectivas, a un pH más básico no es posible llevar a cabo la reacción, además este $\mathrm{pH}$ propicia el aumento en la producción de burbujas de hidrógeno favoreciendo la flotación de los contaminantes. (Piña , Dominguez, \& Ramirez González, 2011)

Ajustado el $\mathrm{pH}$ se procedió con el encendido del sistema manteniendo un voltaje aproximado de 34 Volt (V) y una intensidad de corriente de 8 Amperes. Dado que dependiendo de la naturaleza del agua residual algunos autores han trabajado con un voltaje próximo a $32 \mathrm{~V}$ y una intensidad de corriente aproximada de $3 \mathrm{~A}$ que depende de la densidad de corriente y distancia de las placas, dicho proceso generó espuma color beige (ver figura 2), la cual se removió cada vez que se llenaba el recipiente de reacción.

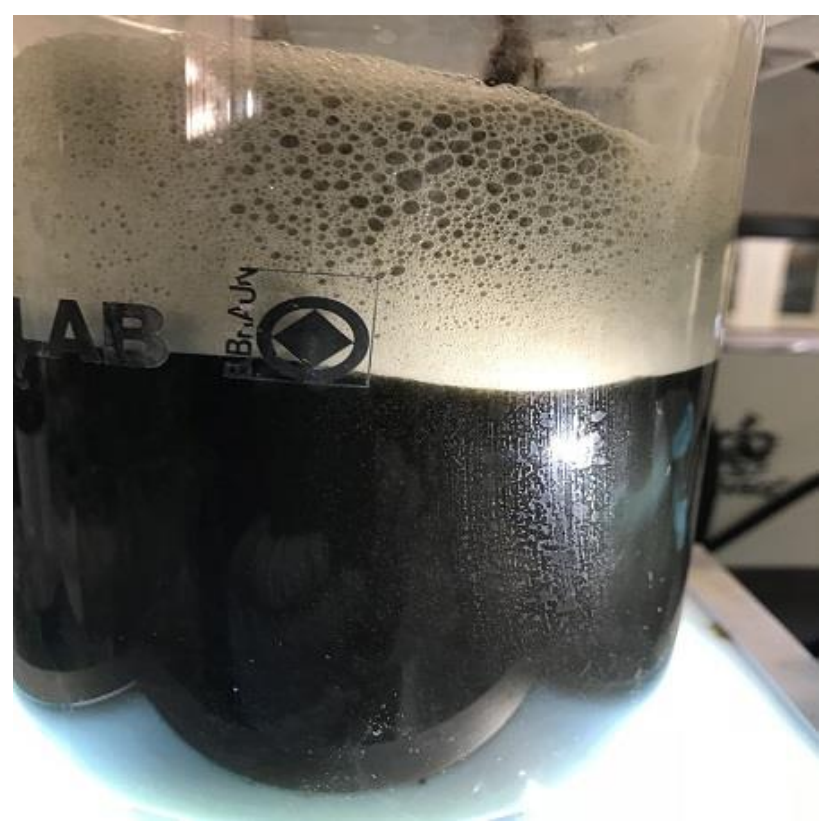

Figura 2 Espuma formada en el proceso

Fuente: Elaboración Propia

Se continuó con el proceso de electrofloculación hasta que ya no se observó la generación de espuma abundante, esto sucedió alrededor de los 5 minutos de funcionamiento, se ha reportado que la mayor remoción ocurre durante los primeros 10 minutos ( (Holt, Barton, $\&$ Mitchell, 2005), la agitación no fue vigorosa con la finalidad de no romper los flóculos generados. Al terminar el proceso se obtuvo un agua de color amarillo claro, sin la formación de precipitados, como se muestra en la figura 3.

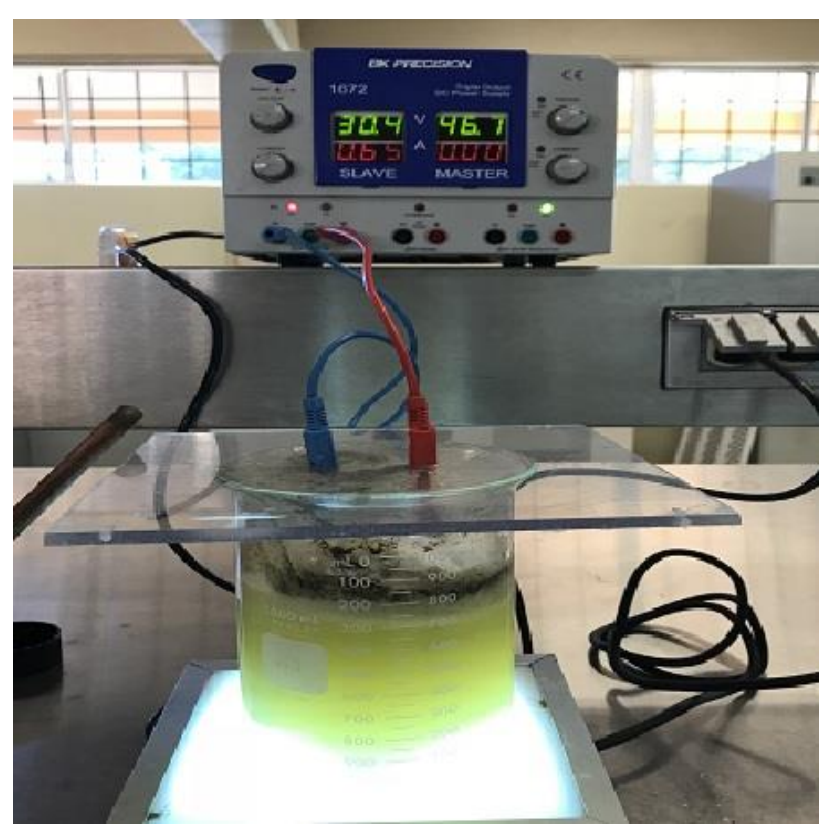

Figura 3 Termino del proceso de electrofloculación. Fuente: Elaboración Propia 
Debido a la apariencia del agua se decidió realizar tratamientos físicos que no afecten el proceso de electrofloculación, en primer lugar se colocó el agua tratada en un recipiente sedimentador con la finalidad de eliminar solidos suspendidos, posteriormente se procedió a filtrar mediante el uso de filtros Whatman número 4, de $150 \mathrm{~mm}$, y finalmente se realizó una última filtración con un filtro compuesto por algodón y carbón activado, repitiendo este último paso de 2 a 3 veces hasta obtener un agua sin color ni olor.

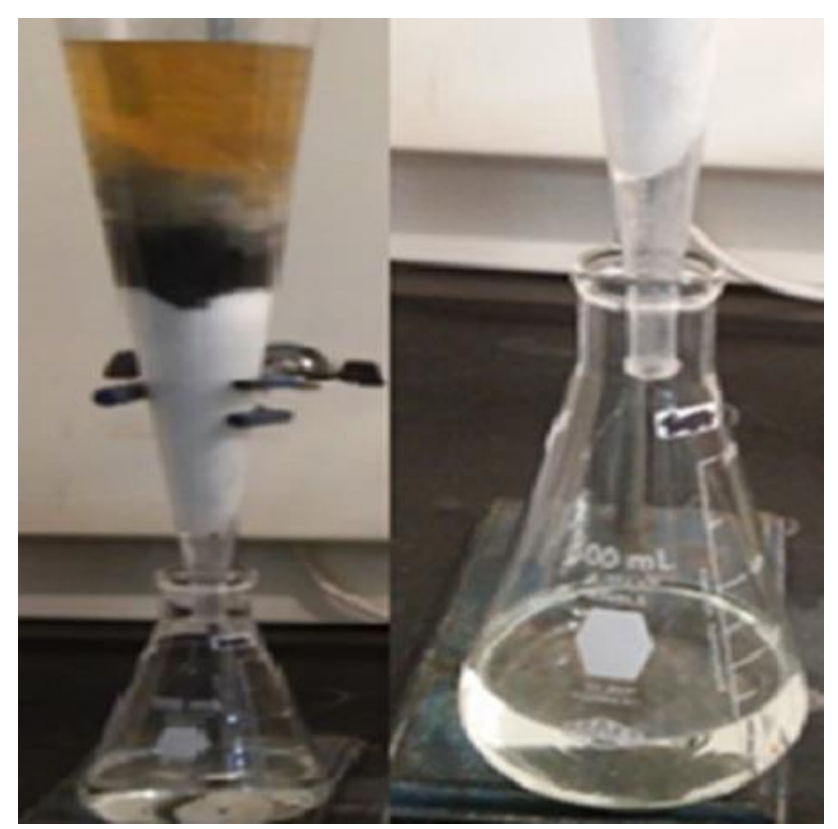

Figura 4 Apariencia final del agua residual tratada Fuente: Elaboración Propia

En la tabla 3, se muestran los parámetros utilizados para cada lote procesado en el sistema de electrofloculación, por cada $900 \mathrm{~mL}$ de agua de entrada en el sistema se recuperan $700 \mathrm{~mL}$ de agua limpia con una apariencia transparente y sin olor, lo que representa un $77 \%$ de recuperación. También es importante indicar que por cada corrida se obtuvieron en promedio $55.43 \mathrm{~g}$ de lodo húmedo y $7.35 \mathrm{~g}$ de lodo base seca.

\begin{tabular}{|l|r|}
\hline \multicolumn{1}{|c|}{ Parámetro utilizado } & Medición \\
\hline Volumen de agua (mL) & 900 \\
\hline pH inicial & 8.50 \\
\hline pH de trabajo & 4.20 \\
\hline Voltaje (V) & 32 \\
\hline Intensidad de corriente (A) & 9.93 \\
\hline Potencia consumida (W) & 268.49 \\
\hline Tiempo de electrofloculación (min) & 5 \\
\hline
\end{tabular}

Tabla 3. Parámetros de trabajo de la electrofloculación Fuente: Elaboración Propia

\section{Etapa 4. Verificación del funcionamiento del sistema}

La tabla 4, presenta los resultados de la determinación de los parámetros físicos, químicos y biológicos realizados al agua residual tratada, mismos análisis realizados al agua antes del proceso de electrofloculación.

\begin{tabular}{|c|c|c|}
\hline Parámetro & $\begin{array}{l}\text { Valor } \\
\text { promedio }\end{array}$ & $\begin{array}{l}\text { Límite máximo } \\
\text { permisible NOM- } \\
\text { 002-SEMARNAT }\end{array}$ \\
\hline $\mathrm{pH}$ & 8.7 & $5.5-10$ \\
\hline $\begin{array}{l}\text { Conductividad } \\
\text { Eléctrica }(\mathrm{mS} / \mathrm{m})\end{array}$ & 12.10 & Sin Especificación \\
\hline $\begin{array}{lll}\begin{array}{l}\text { Grasas } \\
(\mathrm{mg} / \mathrm{L})\end{array} & \text { y Aceites } \\
\end{array}$ & Ausencia & 25 \\
\hline $\begin{array}{l}\text { Sólidos } \\
\text { Sedimentables } \\
(\mathrm{mL} / \mathrm{L})\end{array}$ & Ausencia & 5 \\
\hline $\begin{array}{ll}\begin{array}{l}\text { Nitrógeno } \\
(\mathrm{mg} / \mathrm{L})\end{array} & \text { Total } \\
\end{array}$ & 28 & 40 \\
\hline $\begin{array}{l}\text { Escherichia } \text { Coli } \\
\text { por cada } 100 \mathrm{~mL} \text {, } \\
\text { NMP }\end{array}$ & 93 & Sin Especificación \\
\hline $\mathrm{DBO}_{5}(\mathrm{mg} / \mathrm{L})$ & 150 & 150 \\
\hline $\mathrm{DQO}(\mathrm{mg} / \mathrm{L})$ & 201.6 & Sin Especificación \\
\hline $\begin{array}{l}\text { Salmonella } / 100 \\
\mathrm{~mL}\end{array}$ & Presencia & Sin Especificación \\
\hline $\begin{array}{l}\text { Sólidos } \\
\text { suspendidos totales } \\
\text { (SST), mg/L }\end{array}$ & 100 & $200 \mathrm{mg} / \mathrm{L}$ \\
\hline Dureza $(\mathrm{mg} / \mathrm{L})$ & 317 & Sin Especificación \\
\hline Sulfatos $(\mathrm{mg} / \mathrm{L})$ & 946 & Sin Especificación \\
\hline
\end{tabular}

Tabla 4 Resultados de la determinación de parámetros al agua residual tratada

Fuente: Elaboración Propia

Con respecto a la DBO el valor obtenido se encuentra en el valor límite del promedio diario con una efectividad de remoción del $70 \%$ con respecto al valor establecido antes del tratamiento del agua residual.

Los resultados muestran una disminución del $77 \%$ con respecto a la cantidad de sólidos suspendidos totales, el parámetro se encuentra a la mitad del límite máximo permitido, lo que indica que el tratamiento es efectivo. La DQO también mostró un disminución, aunque la norma de descarga de agua no indican el límite para DQO, es de suma importancia, ya que indica la degradación de la materia inorgánica. Otros de los parámetros importantes en el tratamiento de aguas residuales son los parámetros biológicos, ya que pueden determinar el uso o reúso que se le puede dar al agua residual, esos parámetros son: número más probable de coliformes fecales (Escherichia coli) y Salmonella sp. 
Los resultados demuestran una disminución de alrededor del $56 \%$ en la presencia de Escherichia coli, valores por debajo del límite máximo permisible de contaminantes para agua residual tratada para el reúso de forma directa en servicios al público, 240 NMP/100 mL (Norma Oficial Mexicana NOM-003ECOL-1997, 1998).

Con respecto a Salmonella los resultados indican la presencia en un bajo porcentaje con respecto a la condición inicial del agua residual, lo que representa una remoción de aproximadamente $98 \%$.

Con respecto al reúso del agua para un sistema de acuaponía, podría ser factible debido a que se removieron más del $50 \%$ de los contaminantes, aunque todavía existe la presencia de bacterias patógenas, se han reportado valores $1043 \mathrm{NMP} / 100 \mathrm{~mL}$ como aceptables en ríos (Secretaría de Medio Ambiente y Recursos Naturales SEMARNAT, 2002), aunque para dureza se encuentra dentro de rango de 20 a 350 mg/L (Campos Pulido, López, Avalos, Hoyos, \& Reta Mendiola, 2013).

\section{Agradecimiento}

Se agradece a la empresa ENREMEX, por permitirnos participar en conjunto en el fondo Programa de Estímulos a la Innovación Tecnológica 2016, CONACYT.

\section{Conclusiones}

Mediante la implementación del sistema de electrofloculación, se logró el tratamiento del agua residual proveniente del digestor dando cumplimiento a un gran número de parámetros establecidos en la NOM-002-SEMARNAT1996, el sistema de tratamiento demostró ser efectivo con una reducción mayor al $50 \%$ en la DQO y $\mathrm{DBO}_{5}$.

Con respecto a los valores de $E$. coli se logró una reducción de más del $50 \%$, con un valor final por debajo de $100 \mathrm{NMP}$, lo que representa una cuantificación 10 veces menor al límite máximo permisible (1000 NMP) establecido por la NOM-002-SEMARNAT1996. Derivado de la eficiencia del tratamiento aplicado los valores obtenidos de E.Coli dan cumplimiento con lo establecido en la NOM003-SEMARNAT-1997 que indica un valor menor a 100 NMP de coliformes para uso directo.
En este sentido el agua residual tratada a través de este método puede ser una alternativa para el reúso del recurso hídrico en zonas áridas del país, como es el caso de la ciudad de Tijuana que se caracteriza por una zona de escasa precipitación, con escasas fuentes de agua superficiales y subterráneas, siendo su única fuente de abastecimiento el agua proveniente del río Colorado (Navarro Chaparro, 2010).

Finalmente se puede concluir que se cumplió con los objetivos, ya que se logró la construcción de un prototipo de electrofloculación, y se demostró su efectividad para dar cumplimiento con los límites máximos permitidos para su disposición al sistema de drenaje.

\section{Referencias}

Aldeguer, A., Prats , D., \& Seller, A. (2019). Electrocoagulación en Fangos secundarios en la EDAR de Novelda - Monforte Del Cid. Efectos Sobre la Digetión anaerobia. Orihuela: Universidad de Alicante.

Arango Ruiz, A., \& Garcés Giraldo, L. F. (2007). Diseño de una celda de electrocoagulación para el tratamiento de aguas residuales dela industria láctea. Revista Universidad EAFIT, 43(147), 5667.

Campos Pulido, R., López, A. A., Avalos, D. A., Hoyos, A. A., \& Reta Mendiola, J. (2013). Caracterización fisicoquímica de un efluente salobre de tilapia en acuaponia. Revista Mexicana de Ciencias Agrícolas(5), 939-950.

Chen, G. (2004). Electrochemical technologies in wastewater treatment. Separation and Purification Technology, 38, 11-41.

Holt, P. K., Barton, G. W., \& Mitchell, C. A. (2005). The future for electrocoagulation as a localised water treatment technology. Chemosphere, 59, 355-357.

Mollah, M., Morkovsky, P., Gomes, J., Kesmez, M., Parga, J., \& Cocke, D. (2004). Fundamentals, present and future perspectives of electrocoagulation. Elsevier B.V, 199 -210.

Navarro Chaparro, S. K. (2010). La problemática del agua urbana en la Ciudad de Tijuana, Baja California y algunas alternativas para la gestión sustentable. Tijuana, Baja California, México.

ALFONSO-ALVAREZ, Juan Antonio, MONTAÑO-SOTO, Myriam Tatiana, EATON-GONZÁLEZ, Bernardino Ricardo y VÉLIZ-ZAMORANO, Ana Karina. Evaluación del funcionamiento de un prototipo de electrofloculación para el tratamiento de agua residual proveniente de procesos de biodigestión y tratamiento de agua residual proveniente de procesos de biodigestión y
biocompostaje. Revista de Sistemas Experimentales. 2019 
Norma Mexicana NMX-AA-034-SCFI-2015. (2015). Diario Oficial de la Federación. Análisis de agua medición de sólidos y sales disuelta en aguas naturales, residuales y residuales tratadas método de prueba. México, D.F., México.

Norma Mexicana NMX-AA-072-SCFI-2001. (17 de Abril de 2001). Diario Oficial de la Federación. Análisis de agua determinación de dureza total en aguas naturales, residuales y residuales tratadas método de prueba. México, D.F., México.

Norma Mexicana NMX-AA-074-SCFI-2014. (13 de Enero de 2015). Diario Oficial de la Federación. Análisis de agua medición ion sulfato en aguas naturales, residuales $y$ residuales tratadas metódo de prueba. México, D.F.

Norma Oficial Mexicana NOM-003-ECOL1997. (21 de Septiembre de 1998). Diario Oficial de la Federación. Que establece los límites máximos permisibles de contaminantes para las aguas residuales tratadas que se reusen en servicios al público. Mexico, D.F., México.

Ozyonar, F., \& Karagozoglu, B. (June de 2011). Operating Cost Analysis and Treatment of Domestic Wastewater by Electrocoagulation Using Aluminum Electrodes. Polish Journal of Environmental Studies, 20(1), 173-179.

Piña , S., Dominguez, M., \& Ramirez González. (2011). Revisión de las variables de diseño y condiciones de operación en la electrocoagulación. Revista Mexicana de Ingeniería Química, 10(2), 257-271.

Prieto García, F., Callejas Hernández, J., Reyes Cruz, V., \& Marmolejo Santillán, Y. (2012). Electrocoagulación: una alternativa para la depuración de lactosuero residual. REVISTA AIDIS de Ingeniería y Ciencias Ambientales: Investigación, desarrollo y práctica., 5(3), 5177.

Secretaría de Medio Ambiente y Recursos Naturales SEMARNAT. (2002). Informe de la situación del medio ambiente en méxico. México, México.
Vasudevan, S. (March de 2012). Electrochemistry for Green and Clean Environment. (Central Electrochemical Research Institute, Ed.) Research Journal of Chemistry and Environment, 16(1), 3-6. 